\title{
Initiating advanced laparoscopic surgery in a medical college hospital with basic laparoscopic set up: Is it feasible and safe?
}

\section{Thapa PB}

Assistant Professor, Department of Surgery, Kathmandu Medical College, Sinamangal, Nepal

\begin{abstract}
Background: Laparoscopic surgery involves performing surgery through small incisions in abdominal wall to get access. Primary goal of this procedure is to achieve good cosmetic outcome, reduced post operative pain, early recovery and reduced hospital admission.
\end{abstract}

Objective: The main objective of this study is to see the feasibility and benefit of performing advance laparoscopic surgery in a place where basic laparoscopic surgery is done and to share my experience while performing it.

Materials and methods: A retrospective study of case sheets and discharge summary from $1^{\text {st }}$ May 2008 till $1^{\text {st }}$ August 2009 was done. Altogether eight patients underwent different advanced laparoscopic procedure. Cases done for the first time in the institute and those done by himself were only included. Technical feasibility, use of devices like harmonic scalpel, need for incision extension, operative time, blood product requirement, ambulation and enteral feed, post operative hospital stay and patients satisfaction regarding minimal scars were assessed.

Result: Total eight patients underwent advance laparoscopic surgery. There were two common bile duct (CBD) exploration of which one was transcystic exploration, one total laparoscopic abdominoperineal resection (APR) for rectal cancer, one laparoscopic assisted right hemicolectomy for carcinoma ceacum, one laparoscopic assisted sigmoid colectomy for recurrent sigmoid volvulus, two laparoscopic right nephrectomy for non functioning right kidney, one retroperitoneal pyelolithotomy and one laparoscopic assisted splenectomy for massive splenomegaly with haemolytic anaemia.

All procedures were technically feasible with basic laparoscopic instruments. However harmonic scalpel was required for splenectomy due to difficult hilum dissection. Ureteroscope was used as a choledochoscope in CBD exploration. Blood transfusion was required only in patient with low preoperative haemoglobin. Early ambulation and enteral feed was done within 24 hours in all and within 48 hours in patients who had bowel anastomosis. Post operative hospital stay was 5-8 days. Cosmetic scar was appreciated by all. Although long term oncological outcome is yet to come in malignancy case, biopsy report of laparoscopic APR identified 13 nodes which shows complete nodal dissection on oncological principal basis.

Conclusion: Advanced laparoscopy is feasible, safe and effective in the hand of surgeons performing basic laparoscopic surgeries with guidance from surgeons who have long experience on same procedures but by open method.

Key words: Advanced Laparoscopic Surgery

$\mathrm{W}$ ith advances in minimal invasive surgery and increase in confidence level of laparoscopic surgeon, many advance laparoscopic procedure are feasible and are being performed in Nepal. However, till date no paper have been published regarding pros and cons of performing advance laparoscopic surgery in a setup meant for basic laparoscopic surgery like laparoscopic cholecystectomy, appendectomy and mesh repair. Hence, this study helps to know advantage and disadvantage of advance laparoscopic surgery in a basic laparoscopic set up.
Materials and methods

A retrospective analysis of eight cases that underwent different advance laparoscopic procedures for various disease conditions were included from $1^{\text {st }}$ May 2008 till $1^{\text {st }}$ Aug 2009. Case sheets and discharge summary of each were analysed.

Correspondence

Dr. Prabin Bikram Thapa

Department of Surgery

Kathmandu Medical College Teaching Hospital

E-mail: prabin_bt@rediffmail.com 
All the advanced laparoscopic procedure done first time in this institute and done by the author only was included.

There were two common bile duct exploration for choledocholithiasis of which one was transcystic exploration, one total laparoscopic abdominoperineal resection for rectal cancer, one laparoscopic assisted right hemicolectomy for carcinoma ceacum, one laparoscopic assisted sigmoid colectomy for recurrent sigmoid volvulus, one laparoscopic right nephrectomy for non functioning right kidney, one laparoscopic retroperitoneal right pyelolithotomy and one laparoscopic assisted splenectomy for massive splenomegaly with haemolytic anaemia.

All procedures were done under general anaesthesia. First camera port was placed in umbilicus followed by two working ports to suit the ergonomics for that particular procedure except for retroperitoneal pyelolithotomy. One additional port was placed as per requirement.
Dissection, electrocautery and clipping were done with instruments used in basic laparoscopy. Intracorporal knot tying was done where blood vessels were big for clipping. Suturing if required was done intracorporal except bowel anastomosis. Harmonic scalpel was used only in splenectomy for short gastric vessels and to control ooze in perihilar region before intracorporal tying of splenic vessels was done. Rigid ureteroscope was used as a choledochoscope for CBD stone removal and to check the stone clearance. Laparoscopic assisted procedure was done only for hand sewn anastomosis of colon in two cases. In splenectomy, small midline incision made for retrieval of massive spleen of $18 \mathrm{~cm}$ $x 5 \mathrm{~cm}$ size.

Technical feasibility, instruments other than basic instruments requirement, total duration of surgery, need of incision extension, blood transfusion, early ambulation and enter feed, post operative hospital stay and patients satisfaction regarding wound cosmesis were analysed.

Table 1: Duration and instrument required in the advanced laparoscopic surgeries

\begin{tabular}{|c|c|c|c|c|}
\hline $\begin{array}{l}\text { Total No. } \\
\mathrm{N}=8\end{array}$ & Date of surgery & $\begin{array}{c}\text { Accessory } \\
\text { instruments required }\end{array}$ & $\begin{array}{c}\text { Duration of surgery } \\
\text { in minutes }\end{array}$ & Incision extension \\
\hline $\begin{array}{l}\text { Laparoscopic CBD } \\
\text { exploration } \\
n=2\end{array}$ & $17^{\text {th }}$ November 2008 & Ureteroscope & 90 mins & No \\
\hline $\begin{array}{l}\text { Laparoscopic right. } \\
\text { Nephrectomy } \\
n=1\end{array}$ & $17^{\text {th }}$ March 2009 & No & 180 mins & No \\
\hline $\begin{array}{l}\text { Laparoscopic APR } \\
n=1\end{array}$ & $2^{\text {nd }}$ May 2009 & No & 240 mins & No \\
\hline $\begin{array}{l}\text { Laparoscopic } \\
\text { assisted sigmoid } \\
\text { colectomy } \\
\mathrm{n}=1\end{array}$ & $5^{\text {th }}$ May 2009 & No & 90 mins & For anastomosis \\
\hline $\begin{array}{l}\text { Laparoscopic } \\
\text { Retroperitoneal } \\
\text { pyelolithotomy } \\
n=1\end{array}$ & $23^{\text {rd }}$ June 2009 & no & $120 \mathrm{mins}$ & No \\
\hline $\begin{array}{l}\text { Laparoscopic } \\
\text { splenectomy } \\
n=1\end{array}$ & $28^{\text {th }}$ July 2009 & Harmonic scalpel & $210 \mathrm{mins}$ & For specimen retrieval \\
\hline $\begin{array}{l}\text { Laparoscopic } \\
\text { assisted right } \\
\text { Colectomy } \\
n=1\end{array}$ & $11^{\text {th }}$ August 2009 & No & $180 \mathrm{mins}$ & For anastomosis \\
\hline
\end{tabular}


Table 2: Post operative management and patient satisfaction

\begin{tabular}{|l|c|c|c|c|}
\hline $\begin{array}{l}\text { Total No } \\
\mathbf{N}=\mathbf{8}\end{array}$ & Blood transfusion & $\begin{array}{c}\text { Early ambulation / } \\
\text { enteral feed }\end{array}$ & $\begin{array}{c}\text { Post operative } \\
\text { hospital stay }\end{array}$ & $\begin{array}{c}\text { Patient satisfaction } \\
\text { on cosmesis }\end{array}$ \\
\hline $\begin{array}{l}\text { Laparoscopic CBD } \\
\text { exploration } \\
\mathrm{n}=2\end{array}$ & No & yes $/ 24 \mathrm{hrs}$ & $\begin{array}{c}\text { 3days(trans cystic) } / 5 \\
\text { days }\end{array}$ & satisfied \\
\hline $\begin{array}{l}\text { Laparoscopic right. } \\
\text { Nephrectomy } \\
\mathrm{n}=1\end{array}$ & No & Yes/24hrs & 4 days & satisfied \\
\hline $\begin{array}{l}\text { Laparoscopic APR } \\
\mathrm{n}=1\end{array}$ & 2 units & yes/24hrs & 8 days & satisfied \\
\hline $\begin{array}{l}\text { Laparoscopic } \\
\text { assisted rt. } \\
\begin{array}{l}\text { Colectomy } \\
\mathrm{n}=1\end{array}\end{array}$ & No & Yes/48hrs & 5 days & satisfied \\
\hline $\begin{array}{l}\text { Laparoscopic } \\
\text { assisted sigmoid } \\
\begin{array}{l}\text { colectomy } \\
\mathrm{n}=1\end{array}\end{array}$ & No & Yes/48hrs & 6days & satisfied \\
\hline $\begin{array}{l}\text { Laparoscopic } \\
\text { splenectomy } \\
\mathrm{n}=1\end{array}$ & 2 units & Yes/24hrs & 7days & satisfied \\
\hline $\begin{array}{l}\text { Laparoscopic } \\
\text { Retroperitoneal } \\
\text { pyelolithotomy }\end{array}$ & No & Yes/24hrs & 3 days & satisfied \\
\hline
\end{tabular}

\section{Discussion}

Laparoscopic surgery has promised to improve health related outcomes. Around 20 years after first laparoscopic cholecystectomy, other advanced laparoscopic surgery was initiated. Unlike laparoscopic cholecystectomy none has become the gold standard treatment but has emerged as an alternate treatment modality with better cosmesis, early recovery and safe.

Colorectal malignancy managed by laparoscopic procedure has been a subject of intense investigation. Recent date meta-analysis comprising five randomized controlled trials confirmed its acceptable oncological outcome as primary end point and immediate post operative outcome as secondary end point ${ }^{1,2}$. To satisfy the oncological principle, 12 nodes are to be harvested from the resected specimen where as in our case 13 nodes were identified in histopathological examination.

There is ongoing debate regarding the management of choledocholithiasis. The advantage of laparoscopic common bile duct (CBD) exploration over ERCP followed by laparoscopic cholecystectomy is that it is a one staged procedure. Laparoscopic CBD exploration is limited by its long learning curve and it is technically demanding ${ }^{3}$. Transcystic CBD exploration has high success rate and low morbidity ${ }^{4}$. But its application is in wide cystic duct to negotiate choledochoscope and small stones in the CBD. However, with use of semi rigid ureteroscope as a choledochoscope in transcystic or trans-common bile duct have two advantages; one use of irrigation port and another use of working port for retrieval of stone with use of forceps or dormia.

Laparoscopic splenectomy has been an obvious alternative to open surgery for non enlarged spleen. For massive splenomegaly, it is feasible to mobilise and dissect inside the abdomen. But its manipulation and retrieval is cumbersom ${ }^{5}$. High conversion rate and morbidity are reported in literatures ${ }^{6}$. In my case complete dissection was possible but incision extension was done for its retrieval.

Laparoscopic nephrectomy has been one of the modalities for treatment non functioning kidney ${ }^{7}$. In one patient transperitoneal approach was done for huge hydronephrotic nonfunctioning kidney with use of basic laparoscopic instruments.

Availability of various modalities like extracorporeal shockwavelithotripsyandpercutaneousnephrolithotomy made use of laparoscopic approach minimal for renal stones $^{8}$. Its use can only be if adjunct procedure is required along with stone removal like pyeloplasty. In this case, the indication was lack of PCNL and ESWL as well as large stone. Retroperitoneal approach is unfamiliar compared to transperitoneal approach. 
Acknowledgement

I would like to acknowledge Dr. Deepak Raj Singh (FRCSEd) for his inspiring support and Dr. Dhiresh Kumar Maharjan (MRCSEd) for his contributions in all advance laparoscopic surgery which underwent during this journey.

\section{References}

1. Kuhry E, Schwenk W, Gaupset R, Romild U, Bonjer J. Long-term outcome of laparoscopic surgery for colorectal cancer: A cochrane systematic review of randomised controlled trials. Cancer Treatment Reviews. 2008;34:498504.

2. Jayne DG, Guillou PJ, Thorpe H, Quirke P, Copeland J, Smith AM et al. Randomized trial of laparoscopic-assisted resection of colorectal carcinoma: 3-year results of the UK MRC CLASICC Trial Group. J Clin Oncol. 2007;25(21):3061-8.

3. Handoff JM, Hall JC. Acquiring surgical skills, Br J Surg. 2000;87(1):28-37.
4. Carroll BJ, Phillips EH, Rosenthal R, et al Update on transcystic exploration of the bile duct. Surg laparoscope Endos. 1996;6:453-8.

5. Taragona EM, Balgue C, Trias M. Laparoscopic splenectomy for splenomegaly. In: Kathkhouda N, editor. Surgical disease of the spleen. Problems in general surgery. vol 19. Philadelphia: Lippincott, Williams and Wilkins; 2002.p.95-101.

6. Kercher KW, Mathews BD, Walsh RM, Sing RF, Backus CL, Heniford BT. Laparoscopic splenectomy for massive splenomegaly. Am J Surg. 2002;183:192-6.

7. Eraky I, EL Kappany H, Ghoneim MA. Laparoscopic nephrectomy : mansoura experience with 106 cases. $\mathrm{Br} \mathrm{J}$ Urol. 1995;75:271-5.

8. Micali S, Moore RG, Averch TD et al. Role of laparoscopy in management of renal and ureteric calculi.J Urol. 1997;157:463-6. 